1 Instituto de Pesquisa Econômica e Aplicada (Ipea) - Brasília (DF), Brasil. Centro Universitário Grupo Educacional Ceuma (Unieuro) - Brasília (DF), Brasil. Universidade Federal Fluminense (UFF) - Niterói (RJ), Brasil

Orcid: http://orcid. org/0000-0002-15075844

gaiger@ipea.gov.br

2 Universidade Federal Fluminense (UFF) - Niterói (RJ), Brasil.

Orcid: http://orcid. org/0000-0002-54707349

luanapassos_s@hotmail.com

3 Universidade Federal do Sul e Sudeste do Pará (Unifesspa) - Marabá (PA), Brasil.

Orcid: http://orcid. org/0000-0003-36994468

dyeggorguedes@unifesspa. edu.br

\section{Reforma tributária no Brasil: por onde começar?}

\author{
Tax reform in Brazil: where to begin?
}

Fernando Gaiger Silveira1, Luana Passos², Dyeggo Rocha Guedes $\mathbf{3}$

DOI: $10.1590 / 0103-110420185316$

RESUMO O debate político-econômico nacional, no período recente, tem apontado para a necessidade de o Brasil realizar reformas estruturais que o permitam sair de uma das maiores crises econômicas de sua história. Este texto trabalha, essencialmente, com as questões que envolvem uma Reforma Tributária para o País, realçando o arcabouço teórico que a orienta no plano internacional (a Teoria da Tributação Ótima) e a necessidade de corrigir as principais distorções (diretas e indiretas) oriundas do atual arranjo tributário nacional. Com base nesses aspectos, o objetivo principal do artigo foi discutir, à luz da experiência internacional e do acúmulo teórico e empírico da literatura nacional, caminhos que podem ser trilhados pelo Brasil que contribuam para uma Reforma Tributária que seja ao mesmo tempo promotora tanto de eficiência quanto de equidade. Conclui-se que uma melhor calibração do sistema tributário brasileiro pode ser alçada com a mudança na tributação indireta a favor de um Imposto sobre Valor Adicionado, e que a justiça fiscal, pode ser galgada acentuando a tributação sobre capital e patrimônio, em conformidade com as proposições teóricas da revisão da teoria da tributação ótima.

PALAVRAS-CHAVE Reforma Tributária. Eficiência. Equidade. Tributação Ótima.

\begin{abstract}
The national political-economic debate in the recent times has pointed to the need for Brazil to carry out structural reforms that will enable it to overcome one of the greatest economic crises in its history. This text deals mainly with issues involving a Tax Reform for the country, highlighting the theoretical framework that guides it at the international level (the Optimal Tax Theory) and the need to correct the main (direct and indirect) distortions arising from current national tax arrangement. Based on those aspects, the main objective of the article was to discuss, in the light of international experience and of the theoretical and empirical accumulation of the national literature, the paths that Brazil can follow that contribute to a Tax Reform that is at the same time a promoter of efficiency and equity. It is concluded that a better calibration of the Brazilian tax system can be offset by the change in indirect taxation in favor of a Value-Added Tax, and that tax justice to be able to be increasing taxation on capital and equity, in compliance with the theorical propositions of optimal tax theory.
\end{abstract}

KEYWORDS Tax Reform. Efficiency. Equity. Optimal Taxation. 


\section{Introdução}

Após a Segunda Guerra Mundial, presenciou-se, nos países desenvolvidos, uma mudança de paradigma a favor do papel distributivo da tributação. A tributação sobre a renda por meio da elevação das alíquotas tanto da pessoa física como jurídica se tornou algo importante, com a ampliação da oferta pública e a construção dos Estados de Bem-Estar Social. O Brasil, com um viés menos progressista em termos de alíquotas do imposto sobre a renda do que países desenvolvidos nesse período, ampliou sua margem de tributação sobre os rendimentos de $20 \%$ para $65 \%$ entre os anos de 1940 e a metade da década de $1960^{1}$, embora com ausência de robustez na provisão dos bens públicos, fator que em muito esteve também amparado na estrutura rural e informal da economia, nos níveis elevados de desigualdade, na frágil governança e qualidade institucional, e no poder das elites econômicas.

Todavia, se por um lado o Brasil foi menos progressivo em termos de tributação da renda do que parte dos países desenvolvidos, por outro, seguiu fielmente os preceitos da Tributação Ótima nos anos de 1980 e 1990. Esse período foi marcado por alterações no sistema tributário mundial a favor da eficiência, competitividade e equidade horizontal, bem como pela redução dos tributos sobre o comércio internacional, a consolidação da tributação sobre o valor agregado e a suavização dos níveis e da quantidade de alíquotas do imposto de renda. Assim, do ponto de vista histórico, o Brasil não aderiu, de fato, à onda favorável à promoção da justiça fiscal no período de consolidação dos Estados de Bem-Estar, porém, em sentido contrário, optou pelo caminho da Tributação Ótima cuja justificava seguia dois argumentos: i) suavização da progressividade ou adoção de um imposto de renda linear, e; ii) redução ou eliminação da tributação sobre as rendas oriundas do capital2,3.

Em que pese a estrutura ainda regressiva da tributação no Brasil contemporâneo e o seu baixo impacto redistributivo, é importante sublinhar os avanços alcançados em termos de construção de um Estado de BemEstar Social e do papel que os gastos sociais obtiveram na última década em direção à promoção da justiça fiscal. Desse modo, tendo em mente o potencial da política fiscal, mais detidamente do gasto social para a suavização da pobreza e da desigualdade, é que se deve buscar uma reforma tributária inclusiva, ou seja, promotora de desenvolvimento e equidade. Apesar da atual agenda de viés conservador, em nível global, cujo papel distributivo do Estado tende a ser colocado de lado, o cenário parece ser favorável a uma reforma tributária de cunho solidário. Tal perspectiva se assenta no próprio processo de revisão que a Teoria da Tributação Ótima (TTO) enfrenta, bem como das próprias demandas florescidas nesse período de crise fiscal e econômica pelo qual o Brasil passa.

Posto isso, o objetivo desse texto é discutir, à luz da experiência internacional e do acúmulo teórico e empírico da literatura nacional sobre o tema, propostas que podem orientar uma Reforma Tributária no Brasil promotora de eficiência e equidade. Para isso, o artigo é dividido em três seções além desta introdução e das considerações finais. Na primeira seção, apresenta-se a teoria mainstream da tributação, a TTO, realçando suas principais críticas. A segunda seção introduz o debate sobre Reforma Tributária no Brasil. Já a terceira seção discorre sobre algumas propostas para reformulação da tributação direta e indireta no País com um viés revisionista sobre a teoria tributária convencional.

\section{Tributação Ótima: princípios e a hora da revisão}

A TTO foi - e, em certa medida, ainda é uma das principais bases teóricas a inspirar a construção dos sistemas tributários em nível internacional. Pautada nos conceitos, modelos e métodos analíticos do Equilíbrio 
Geral da Teoria Neoclássica, tal teoria procura apontar os caminhos que devem ser seguidos pelos sistemas tributários para que tenham menor efeito distorcivo na decisão dos agentes ao mesmo tempo que possibilita uma arrecadação mais eficiente.

Para Barbosa e Siqueira 4 , o arcabouço analítico da TTO tem por pressupostos os critérios de otimalidade, uma vez que considera a especificação das preferências dos agentes econômicos e do bem-estar social, e a modelagem das questões de eficiência e equidade. Para tanto, a solução ideal, segundo essa teoria, seria tributar as habilidades naturais dos indivíduos, uma característica definidora da capacidade de adquirir renda, e que constitui elemento de diferenciação pessoal dos contribuintes. Todavia, essas informações imprescindíveis para a determinação dos tributos são privadas e não estão perfeitamente reveladas na economia, o que dificulta a definição ótima da tributação.

Se as informações privadas dos indivíduos pudessem ser obtidas a um custo zero, o governo poderia ter uma tributação perfeita ao valer-se do lump sum tax, um imposto de montante fixo que é eficiente na medida em que sua arrecadação não depende do comportamento dos agentes, e, sim, de suas características. Como, na prática, isso não é possível, o governo fica restrito à utilização de impostos que distorcem a decisão dos agentes e, desse modo, geram ineficiências. Assim, dada a impossibilidade de utilizar a solução ideal do tipo lump sum, deve-se acessar a segunda melhor solução (second best), qual seja, de o fisco considerar indicadores - renda, consumo, patrimônio, entre outros - que lhes possibilite apreender de modo indireto as habilidades e capacidade de contribuição dos indivíduos.

Uma das grandes contribuições da TTO, portanto, é apontar a necessidade de, na elaboração dos sistemas tributários, considerar os efeitos distorcivos (efeito-renda e efeito-substituição) nas decisões dos agentes econômicos que, ao cabo, podem refletir em uma arrecadação muito aquém do que se pretendia. Para Lagemann ${ }^{5}$, as recomendações da Tributação Ótima dizem respeito à montagem de um sistema tributário que considere os distintos comportamentos da demanda de bens e serviços e da oferta de fatores de produção, estando atento ao trade off entre as soluções eficientes e justas. Em síntese, para o autor, as proposições dessa teoria estão relacionadas com uma tributação sobre o consumo e sobre a renda. No primeiro caso, o imposto deveria considerar a regra da complementariedade na qual os bens complementares ao lazer devem apresentar maior peso da tributação do que os bens que apresentam menor complementariedade ao tempo livre. No segundo, quando houver a possibilidade de tributar a renda do trabalho, devem-se aplicar alíquotas marginais nulas nos extremos inferior e superior, apesar de a teoria não definir a alíquota para as faixas intermediárias de renda. Esse resultado deriva do pressuposto de que a oferta de trabalho se mostra elástica para os mais habilitados, sendo sensível a alterações na renda pós-tributação. Assim, alíquotas marginais elevadas impactariam negativamente o trabalho mais qualificado e produtivo ${ }^{6}$. É importante destacar que, quanto ao imposto de renda do capital, a Teoria considera que ele não necessariamente precisa compor o sistema tributário ideal ${ }^{5}$.

Entre os modelos que sustentam a TTO, o pioneiro foi o de Ramsey ${ }^{\mathbf{7}}$ que, adotando hipóteses bem simplificadoras e levando em conta apenas um agente representativo, demostra que as alíquotas ótimas sobre consumo devem apresentar relação inversa com a elasticidade-preço de demanda. Esse modelo, que considera apenas questões de eficiência na economia, é regressivo, dado que, pela regra do inverso das elasticidades, os bens de primeira necessidade, que possuem menor elasticidade-preço da demanda, deveriam ter uma alíquota mais elevada.

Por mais de 40 anos, esse modelo teve centralidade na definição da estrutura do 
imposto ótimo sobre o consumo, pois seu aprimoramento se deu apenas com o modelo de Diamond e Mirrlees ${ }^{8}$ cujas considerações distributivas passaram a ser levadas em conta. O modelo de Diamond e Mirrlees ${ }^{8}$, em termos práticos, é uma extensão do resultado de Ramsey ${ }^{7}$ ao considerar uma economia com vários agentes. Com a modelagem desses autores, a Tributação Ótima passou a, de fato, incorporar o conflito entre eficiência e equidade. Desse modo, quanto maior for a preocupação social com os agentes mais pobres, menor deverá ser a variação da demanda desses agentes devido ao imposto. A estrutura ótima da tributação tem que buscar o equilíbrio entre eficiência e equidade; e, para tanto, a estrutura das alíquotas deve ser determinada pela seletividade, de acordo com a ponderação dada aos bens consumidos pelos mais pobres. Portanto, enquanto as considerações apenas relacionadas com a eficiência apontam para uma maior tributação de bens necessários, as questões distributivas revelam a necessidade de algum tipo de progressividade na tributação sobre bens.

Vale destacar que muitas controvérsias rondam a TTO, sendo que as críticas se direcionam aos argumentos teóricos e econômicos que a sustentam, em especial, àqueles relacionados com economia do bem-estar e com sua pouca aderência à realidade. A suposição de que os indivíduos agem como agentes racionais, com informações plenas e que têm livre escolha entre o trabalho e tempo livre mudando suas decisões conforme o nível que se estabeleça a tributação é um exemplo dessa distância entre teoria e realidade observável.

Além dos problemas de essência, a TTO é limitada, pois desconsidera em sua modelagem os custos administrativos, incerteza e objetivos macroeconômicos. Ademais, ela não define claramente quais devem ser as alíquotas dos impostos sobre consumo e renda. Corroborando essas ideais, Lagemann ${ }^{5}$ aponta que a presumida ordem política e aplicabilidade das recomendações dessa Teoria é tida como frágil pelos adeptos da public choice, uma vez que é inconsistente considerar o homem um egoísta maximizador da própria utilidade, mas que, na atividade política, age como um benfeitor, maximizando o bem-estar social. Barbosa e Siqueira ${ }^{4}$ também destacam que, a despeito de essa teoria propor em sua análise a combinação dos critérios de equidade, simplicidade e eficiência, pouca atenção é concedida ao critério da simplicidade e essa compreende uma de suas maiores limitações teórica.

Gobetti $^{6}$, por sua vez, ressalta outra falha na TTO: as recomendações em relação a não tributação do capital. Para o autor, a proposição de que a parcela da renda poupada não deveria ser tributada porque já o foi na forma de salários e que criaria um incentivo para consumir mais renda no presente é pouco realista, o que tem feito expoentes economistas apontarem inclusive os benefícios da tributação sobre a poupança.

É importante sublinhar que as críticas à TTO também devem ser encaixadas no campo dos resultados que suas proposições geraram, porque embora nenhum sistema tributário tenha sido modelado completamente conforme suas orientações, as influências exercidas foram muitas. Nesse campo, Piketty ${ }^{9}$ e seguidores dão grande contribuição ao desnudar a concentração do capital no século XXI e a premente demanda pela ressignificação da Tributação Ótima e seus preceitos de não tributação dos mais ricos e do capital. Gobettí aponta também que a espinha dorsal dos teoremas e modelos da Tributação Ótima tem sido revisitada, em especial as proposições de menor progressividade tributária e menor tributação das rendas do capital, tanto por economistas neoclássicos da nova geração como pelos da velha guarda.

Nos momentos de crise, como a que o mundo enfrenta atualmente, as teorias e suas prescrições são analisadas e revistas em seus alcances e fragilidades, não estando a TTO alheia a essa realidade. Assim, uma onda de reformas propostas por uma corrente, por 
assim dizer, mais progressista da TTO tem colocado em relevo a necessidade de majoração da tributação do capital, do patrimônio e das altas rendas das pessoas físicas, com reflexos positivos tanto para a justiça como para a arrecadação fiscal.

Tendo em mente esse cenário de propostas mais favoráveis à equidade pela própria TTO, que por muito tempo foi completamente avessa ao uso da tributação para fins distributivos, cabe ponderar a tônica da reforma tributária brasileira, o que será envidado na próxima seção.

\section{Reforma Tributária no Brasil: o debate}

Não sintonizado com o movimento internacional, as ideias e interesses presentes no debate da reforma tributária brasileira não acompanham o movimento de renovação do pensamento dominante na mesma proporção. Essa revisão da tributação tem se dado tanto na TTO como nas proposições de organismos multilaterais em relação à progressividade tributária, com foco na tributação sobre a pessoa física, em especial nos rendimentos não relacionados com o trabalho, rendimentos do trabalho e de aposentadorias. Ademais, esses atores vêm defendendo que alíquotas marginais superiores e a tributação sobre o capital não implicam perdas de eficiência como outrora se imaginava ${ }^{10}$. Essa mudança se consolida não pela ruptura com o arcabouço analítico da TTO, mas com seu enriquecimento com hipóteses mais realistas e com a incorporação de contribuições da economia comportamental e da desigualdade. Diamond e Saez ${ }^{\mathbf{1}}$ chegam a alíquotas máximas para a pessoa física da ordem de $60 \%$, considerando elasticidades oferta de trabalho não tão elevadas - menores de 0,9 - e baixo grau de elisão $0^{6}$.

O debate mundial sobre tributação hoje comparece mais consensual em relação à conclusão de que a tributação progressiva sobre a renda não implica obstáculos ao crescimento econômico, e que seu emprego é fundamental para se reduzir a desigualdade de renda. Esse debate, no entanto, não parece ofuscar o papel central dos gastos públicos sociais para promoção da equidade, apenas se coadunando com a busca de uma sociedade mais justa e solidária.

No caso brasileiro, as resistências e dissensos em relação a uma reforma tributária perpassam diversos setores e grupos de interesses que terão perdas se as mudanças tiverem a tônica internacional. Assim, há bloqueios, pelos mais e menos conservadores, tanto na direção de uma reforma tributária que reduza a carga dos tributos indiretos como uma que amplie a tributação sobre a renda da pessoa física e sobre a riqueza. Os argumentos evocados são que, dado o nível de renda, o grau de informalidade e a necessidade de atração de capitais/poupanças, não parece salutar alterar significativamente a composição da carga, devendo a reforma se concentrar em dois problemas: o caráter disfuncional dos tributos indiretos e a heterogeneidade de tratamento das contribuições sobre salários e rendimentos para o financiamento previdenciário. Ou seja, defendem a harmonização da tributação indireta, com base no valor adicionado e no destino do produto, e sustentam que se pode reduzir o custo das contribuições sobre a folha com alterações no sistema de proteção social.

Há bloqueios na reforma também por parte dos próprios defensores da justiça fiscal, pautada no receio de que as mudanças regridam a provisão afiançada pelo Estado de Bem-Estar. Nesse terreno, são acionadas preocupações com a dissociação entre os tributos e contribuições com as políticas sociais, que para esses atores é imperativo para a sua manutenção.

No entanto, que muitas vezes fica escamoteado no debate em relação à provisão estatal é a captura de certos benefícios fiscais pelas elites econômicas, e a própria regressividade que esteia os gastos. Embora hoje o país conte com um sistema previdenciário, 
de educação básica e de saúde pública com índices de cobertura muito expressivos, o perfil do financiamento é regressivo. Isso porque suas fontes de financiamentos são os tributos sobre o consumo e sobre a folha. Efetivamente, o PIS/Cofins (Programa de Integração Social/Contribuição para 0 Financiamento da Seguridade Social) e o Imposto sobre Circulação de Mercadorias e Serviços (ICMS) são fundamentais no financiamento da seguridade, da educação e da saúde públicas, respectivamente; e, como dito, os principais gastos sociais contam com arcabouço legal em que as vinculações a fontes específicas de financiamento têm papel central, o que se observa, por exemplo, no financiamento da seguridade (previdência, assistência e saúde), no salário educação e nos mínimos constitucionais para educação e saúde. Tem-se, portanto, um conjunto de vinculações entre fontes - tributos e contribuições - e rubricas de gastos, o que torna a estrutura de gastos bastante rígida. Logo, ao se buscar alterar a composição dos tributos, há que se propor necessariamente alterações nas regras e vinculações relativas ao gasto social. O que, implica, por outro lado, mudanças nas relações federativas, pois a harmonização e a redução da tributação indireta reduzem a discricionariedade dos estados e municípios que, junto com o crescimento de importância dos impostos sobre renda e riqueza, alteram a importância das bases de incidência e o peso das transferências entre os entes. Ademais, não se tem segurança quanto aos efeitos sobre o volume de recursos disponíveis aos entes subnacionais e para as políticas sociais. Sendo assim, as pactuações necessárias para uma reforma tributária não são, em nada, triviais, na medida em que podem afetar privilégios e proteções asseguradas na Carta Magna.

Cabe apontar ainda que, dado o tamanho da carga tributária nacional, quando comparado a países de renda similar, os diversos atores sociais se mostram reticentes em apoiar efetivamente mudanças mais expressivas no sistema tributário, pois a mudança na composição pode afetar as finanças dos governos, as rubricas de gastos, os setores produtivos e as regiões. Efetivamente, coloca-se em cheque alterações no atual desenho do sistema em razão das incertezas quanto aos seus efeitos na arrecadação e na discricionariedade dos entes federados, bem como nas fontes de financiamento das políticas públicas, notadamente as de caráter social. Tais inseguranças implicam, assim, pouca disposição em sustentar mudanças no arcabouço tributário, mesmo naquilo que se conta com grande consenso ou necessidade.

Por conseguinte, não há como realizar uma reforma tributária sem processar alterações no desenho do financiamento das políticas sociais e nas obrigações e capacidades dos entes federados.

No atual quadro, é possível alimentar esperanças de mudanças em duas direções que se coadunam com as tendências observadas nos países centrais, são elas: i) o fortalecimento do Imposto sobre Valor Agregado (IVA) com ampliação da base de incidência, em que a tributação sobre serviços e a economia digital se destacam, e; ii) a redução dos tratamentos diferenciados aos rendimentos de pessoas físicas oriundos do capital. Concretamente, é de se esperar que sejam harmonizados os tributos indiretos e que a tributação sobre a renda atinja aos lucros e dividendos distribuídos. Não se pode creditar esse relativo consenso na tributação de lucros e dividendos aos novos ares do mainstream econômico, mas, sim, à necessidade de ampliar os recursos fiscais, dada a situação crítica das contas governamentais. Essa mudança pró-equidade em função da situação fiscal ocorreu, recentemente, em estados e municípios que, com alterações nas alíquotas e na progressividade do Imposto de Transmissão e Causa Mortis e Doação (ITCMD) e do Imposto Predial e Territorial Urbano (IPTU), ampliaram as receitas desses impostos.

Em relação às contribuições sobre a folha salarial, o debate se concentra na necessidade de ampliar as fontes de financiamento 
da previdência social, uma vez que o quadro atual e as tendências no mercado de trabalho vêm fragilizando as fontes de tributação ligadas às relações assalariadas. Ademais, os tributos e contribuições incidentes sobre a folha salarial impactam negativamente a competitividade dos bens e serviços no mercado internacional, pois não é possível a desoneração das contribuições sobre a folha, em razão da impossibilidade de individualizá-las por bem ou serviço.

É com esse norte que se assiste às mudanças no financiamento da proteção social em direção ao emprego de outras bases tributárias, como o IVA e o Imposto de Renda de Pessoa Física (IRPF). No caso brasileiro, a desoneração das contribuições patronais sobre a folha, instituídas a partir de 2012, buscava melhorar as condições de competitividade da economia afetada pela continuada valorização cambial. A experiência das desonerações, assim como da constituição do regime tributário simplificado para as micro e pequenas empresas (Simples), mostra o risco de medidas voltadas para determinados setores e tipos de empresas de serem capturados por outros grupos que não o público objeto desses benefícios tributários. Assim, as desonerações que se destinavam em sua origem a três setores, os mais afetados pela competição internacional, foram sendo concedidas a outros setores produtivos, chegando a atingir dezenas deles. Já no caso do Simples, o limite de faturamento da empresa para inscrição no regime é de cerca de US\$ 1,2 milhão, quase dez vezes superior ao segundo maior limite em vigor nos países que contam com programas similares. Mudanças no sentido de reduzir os setores beneficiados pela desoneração da folha e o limite de faturamento apresentam enormes obstáculos políticos, com a produção legislativa recente atuando em sentido contrário.

Por fim, a discussão sobre tributos ambientais e dos incidentes sobre a exportação de commodities tem presença marginal no debate da Reforma Tributária brasileira, porém observa-se, no cenário internacional, a criação de tributos de corte ambiental e do emprego da taxação sobre exportações de produtos primários com baixo valor agregado.

\section{Em busca da eficiência e equidade: a reforma necessária para o Brasil}

\section{Propostas para reformulação da tri- butação indireta}

Como destacam os manuais de finanças públicas, o IVA constitui o mecanismo par excellence de neutralidade tributária, uma vez que incide sobre todas as etapas do processo de produção independentemente da sua organização. Considerando esse aspecto relacionado com um imposto sobre o consumo de bens e serviços e com a atual composição da carga tributária brasileira, cuja centralidade da arrecadação está baseada na tributação indireta, o debate em torno de uma reforma do sistema tributário nacional deve: i) considerar propostas que visem corrigir o atual peso da composição dos tributos indiretos e diretos na carga tributária total do País, sem prejudicar a sustentabilidade entre receitas e gastos, e; ii) reorganizar a estrutura de regimes especiais como isenções e incentivos fiscais por meio de uma reformulação simplificadora baseada na fusão de tributos sobre bens e serviços e criação de um IVA em linha com a experiência tributária internacional. Assim, a apresentação de uma reforma tributária baseada nas alterações instrumentais do atual arranjo de tributação indireta no Brasil destaca algumas ideias essenciais relacionadas com o princípio do destino, a base de cálculo do imposto, alíquotas, bem como aspectos que consideram fiscalização e arrecadação.

Diferentemente dos padrões internacionais, que adotam, em sua maioria, o IVA como principal imposto sobre o consumo, a tributação 
sobre bens e serviços no Brasil é feita com base em quatro tributos, são eles: i) PIS/Cofins e o Imposto sobre Produtos Industrializados (IPI), que competem a União, e; ii) o ICMS e o Imposto Sobre Serviços de Qualquer Natureza, ISS(QN), que são, respectivamente, de competência dos estados e municípios.

Em linhas gerais, o regime do PIS/Cofins tem ampla base de tributação, incide apenas sobre as empresas e é dividido em dois, um cumulativo e outro não cumulativo. Enquanto o regime cumulativo aplica uma alíquota de $3,65 \%$ sobre a receita da empresa e incide sobre todas as etapas do processo de produção, o regime não cumulativo, criado em substituição ao regime cumulativo, entre os anos de 2003 e 2004, aplica uma alíquota de 9,25\% sobre o valor adicionado. Os setores industriais, de cadeia produtiva longa, durante o tempo, migraram para o regime não cumulativo, enquanto o setor de serviços permanece no regime cumulativo. $\mathrm{O}$ IPI, por sua vez, apesar de não ser cumulativo, possui muitas alíquotas, e a incidência é definida por uma tabela específica e bastante detalhada. Além disso, apesar de incidir sobre a industrialização, ocorre indefinição acerca de onde termina o aspecto industrial do produto e onde começa o da distribuição - em específico, tais indefinições geram contencioso $^{\mathbf{1 2}}$ que é contornado, em geral, por regimes especiais. Ademais, o ISS $(\mathrm{QN})$ é um tributo cumulativo que onera os investimentos e cuja indefinição a respeito de onde termina a sua incidência se confunde com a base de incidência do ICMS ${ }^{13}$.

Além desses fatores que tornam o sistema tributário nacional complexo, contudo, soma-se a eles: i) o elevado tempo despendido com obrigações tributárias acessórias (2.600 horas/ano, mais que o dobro do segundo colocado no ranking do Banco Mundial); ii) a 'Guerra Fiscal', e; iii) a quantidade de normas tributárias vigentes - mais de 25 mil normas atualmente, segundo o Instituto Brasileiro de Planejamento Tributário (2016) ${ }^{\mathbf{1 4}}$ - cuja principal causa é a liberdade dos entes da federação para definição delas. Vale destacar que esses são apenas alguns exemplos que contribuem para a atual complexidade do sistema tributário nacional sobre bens e serviços. Com vistas a corrigir alguns desses problemas, a adoção de um modelo novo de tributação no País passa, necessariamente, pela reformulação da tributação indireta por meio da adoção de um IVA que incida sobre todas as operações que envolvam os bens e serviços. No entanto, para evitar efeitos distorcivos principalmente no lado da arrecadação e, como já apontado, desequilíbrio político em função das necessidades dos entes federados, é importante que as mudanças, ao invés de pontuais - marca histórica da estrutura tributária recente ${ }^{15}$-, sejam feitas de modo gradual, ou 'fatiado', com objetivos bem definidos de curto, médio e de longo prazo.

Desse modo, primeiro haveria a necessidade de racionalizar a gestão por meio da distribuição das competências pela especialização das bases, ou seja, ao invés de manter a União responsável por todas as bases, as competências seriam distribuídas entre os entes da federação por base de incidência do tributo, o que permitiria a especialização das administrações tributárias, dotando-as de mais eficiência na execução das atividades de fiscalização e arrecadação. Diferentemente do modelo atual, essa nova distribuição manteria a União responsável pelos tributos relacionados com a renda, com a previdência e com os regulatórios, como a Contribuição de Intervenção no Domínio Econômico (Cide), por exemplo, enquanto os estados seriam responsáveis pelos de consumo e de previdência dos seus funcionários; e os municípios, por aqueles relacionados à propriedade e previdência dos seus servidores.

Segundo, no atual modelo, o imposto sobre circulação de mercadorias é cobrado de maneira dividida, ou seja, no estado de origem destas, o que equivale a tributar a produção, e no destino das mercadorias, o que equivale a tributar o consumo. Essa característica cria fortes estímulos para que os estados utilizem o imposto com outras finalidades que não a de 
arrecadação tributária. No País, esses estímulos têm contribuído para a conhecida 'Guerra Fiscal' que, apesar de ilegal, tornou-se prática comum entre os estados. Assim, uma medida que corrigiria tal distorção seria utilizar um IVA que prezasse apenas pelo princípio do destino na tributação.

Terceiro, para evitar o problema da cumulatividade e não neutralidade na tributação sobre o consumo, bem como ampliar os objetivos arrecadatórios, a base de cálculo do imposto deve ser ampla e clara, qual seja: o IVA deve incidir sobre o valor das operações com bens e serviços - lidando também, como anteriormente esboçado, com a nova economia da informação (bens intangíveis etc.) e descontar o imposto pago nas operações anteriores da cadeia de produção. Além de garantir que o tributo incida apenas sobre o valor agregado dos produtos, tal medida tornaria o sistema mais simples, pois não restringiria o ressarcimento do crédito dos valores pagos ao longo da cadeia (salvo nos casos de exceção) e, por consequência, faria com que o sistema fosse eficaz.

Em acordo com as medidas anteriores, a quarta e quinta medidas deveriam enfatizar a alíquota do IVA e os aspectos relacionados com a legislação, fiscalização e arrecadação. O IVA ideal, como aponta a literatura, segue com alíquota única ou com poucas alíquotas para não distorcer o tributo. A Dinamarca adota uma alíquota única de $25 \%$, enquanto Portugal, Irlanda e Bélgica, por exemplo, possuem três tipos de taxas para o IVA, a normal, a intermediária e a reduzida. As dificuldades de aplicação de uma taxa única no Brasil, como destacadas, são diversas, desde a necessidade de arrecadação de cada ente da federação, bem como as especificidades dos bens e serviços prestados etc. Uma opção que contornaria tais divergências no País seria a adoção de dois IVA, um federal e outro subnacional, os quais consolidariam as bases do PIS/Cofins, ICMS e ISS(QN), respectivamente.

Além disso, alguma forma de tributação seletiva sobre bens cujo consumo traz consigo externalidades negativas deve ser desenhada nesse novo arranjo tributário. Nesse quesito, a legislação deve ser precisa para garantir simplificação para o contribuinte e capacidade de fiscalização dos órgãos competentes ${ }^{\mathbf{1 4}}$. Por isso, seria importante uma legislação única que abrangesse os dois tributos, garantindo a autonomia dos Estados para fixar as alíquotas, harmonizando os interesses dos entes da federação e dos contribuintes.

Ademais, é importante ponderar que tais medidas, mesmo que corrijam as distorções relacionadas com a neutralidade do tributo, devem compensar seus efeitos regressivos. A ampla base de incidência com aplicação de uma ou poucas alíquotas implicará a reoneração dos chamados produtos da cesta básica, beneficiados por desonerações e isenções pelo governo federal e por várias unidades da federação e poderia alcançar também os serviços que atualmente são pouco tributados. É por conta desses riscos que se defende que tais alterações sejam realizadas de maneira gradual e que se façam acompanhar de outras que permitam reduzir o peso dos tributos indiretos, como a ampliação da tributação sobre a renda, a riqueza e o patrimônio, tema da subseção que se segue.

Logo, uma reformulação que respeitasse, de modo geral, tais medidas e que fosse realizada de modo gradual, considerando as dificuldades políticas e econômicas que envolvem os diversos atores da sociedade, traria benefícios, pois: i) tornaria o sistema de tributação indireta do Brasil mais enxuto; ii) melhoraria a qualidade das normas tributárias bem como a sua interpretação, e; iii) dada a racionalidade a que estaria submetido, garantiria maior segurança jurídica às relações de produção e comércio nacional.

\section{Propostas para reformulação da tri- butação direta}

Dois fatos chamam a atenção no que diz respeito à tributação direta no Brasil: a reduzida expressão do IRPF e o peso relativo da tributação incidente sobre a pessoa jurídica. 
Efetivamente, enquanto os tributos sobre a renda da pessoa física respondem por menos de $10 \%$ da carga tributária brasileira, para a média dos países da Organização para a Cooperação e Desenvolvimento Econômico (OCDE), essa participação é da ordem de um quarto. Por outro lado, a participação dos tributos sobre a renda da pessoa jurídica é bastante semelhante, ao redor de $9 \%$ da carga tributária. Adiciona-se a isso a reduzida importância dos tributos patrimoniais na carga tributária, em especial nos recorrentes - IPTU e Imposto sobre a Propriedade Territorial Rural (ITR) - e nos incidentes sobre a riqueza - ITCMD e Imposto sobre Grandes Fortunas (IGF). Concretamente, no caso brasileiro, esses tributos patrimoniais respondem por $2 \%$ da carga tributária, ao passo que, na média dos países da OCDE, tal participação é superior a $4 \%$.

É patente, portanto, a baixa tributação sobre a renda da pessoa física no Brasil, que se deve, de um lado, às isenções, com destaque para a concedida aos lucros e dividendos distribuídos, as deduções e a reduzida alíquota marginal superior. De outro, o nível de renda e o grau de informalidade da economia nacional reduzem a base de incidência do IRPF, característica sublinhada por aqueles analistas que sustentam não haver espaço para o crescimento da tributação sobre a renda da pessoa física. Ainda que se conte com esse limite quanto ao universo da população objeto do imposto de renda, o tratamento preferencial aos rendimentos do capital e o cipoal de deduções e isenções respondem de modo substancial pela reduzida participação do imposto de renda e por sua atenuada progressividade. Gobetti e Orair ${ }^{1}$ mostram, com base nos dados do ano calendário 2013, quão reduzidas são as alíquotas efetivas, com os maiores valores situando-se ao redor de $12 \%$ para os declarantes com renda anual entre $R \$ 162,7$ mil e $R \$ 325,4$ mil - ao redor de 20 a 40 salários mínimos mensais. A partir de então se reduzem, chegando a somente $6,7 \%$ para as pessoas com rendimentos anuais superiores à $\mathrm{R} \$ 1.301,8$ mil -, cerca de 160 salários mínimos anuais.

Há que sublinhar ainda a opacidade entre os rendimentos do trabalho e do capital decorrente da transmutação de pessoa física em pessoa jurídica que os sistemas simplificados de tributação possibilitam, tornando rendimentos caracteristicamente do trabalho, logo sujeitos à tributação progressiva, em rendimentos do capital, que contam com isenção do imposto de renda. Efetivamente, a isenção dos rendimentos oriundos de lucros e dividendos distribuídos e dos ganhos de sócios de micro e pequenas empresas tornam inúmeras relações de trabalho e assalariamento em relações de caráter comercial, com os rendimentos se configurando como oriundos de lucros e dividendos. Esse fenômeno denominado de 'pejotização' não se deve, no entanto, somente à menor oneração sobre os rendimentos do capital, mas, também, pela possibilidade de se reduzir os custos com os tributos destinados à previdência, no caso, as contribuições incidentes sobre a massa salarial.

Assim, as propostas de alterações na tributação direta passam necessariamente por combater a suboneração das rendas do capital na pessoa física, mas, também, pela redução da tributação incidente sobre a folha, pelo aprimoramento, por meio da melhor focalização, das políticas de inclusão previdenciária e fiscal, e pela concessão de benefícios fiscais relacionados aos investimentos. Outrossim, como no caso dos tributos indiretos que se busca reduzir e harmonizar, as mudanças na tributação direta requerem alterações nos esquemas de financiamento e de gestão das diversas políticas públicas: educação, saúde, previdência, assistência, entre outros.

No que concerne ao IRPF, o fim da isenção de lucros e dividendos e dos rendimentos/ lucros dos sócios de micro e pequenas empresas é o primeiro passo que se concretizará em curto espaço de tempo, mais, como dito, pela necessidade de buscar fontes de 
arrecadação no atual momento de crise fiscal do que pelos efeitos redistributivos. Como tais rendimentos serão tributados é assunto controverso, havendo, grosso modo, duas propostas: aplicar a tabela progressiva ou tributar linearmente em $15 \%$, que é a alíquota modal aplicada aos ganhos realizados em operações nos mercados financeiros. Podese, assim, preservar determinados benefícios para os rendimentos de capital na pessoa física ou tratar igualmente as duas fontes de renda. Vale destacar que, mesmo, nos países que seguem o modelo amplo, concedem-se benefícios aos ganhos de capital de longo prazo e a outras modalidades de poupança. Há um leque de modelos duais, que se distinguem pelos tipos de tratamento concedidos a determinados rendimentos do capital, com destaque para aplicação de alíquotas e/ou progressividade menores ou mais brandas, e para a aplicação de alíquotas proporcionais a rendimentos selecionados.

A tributação sobre os rendimentos do capital na pessoa física requer avaliar o desenho da tributação sobre a pessoa jurídica. Os modelos duais, ao concederem determinados benefícios aos rendimentos do capital na pessoa física, objetivam integrar a tributação da renda da pessoa física com a tributação da pessoa jurídica, com vistas a dar coerência à tributação sobre os rendimentos do capital, conceder tratamento isonômico às diferentes fontes de renda, reforçar a progressividade dos rendimentos do trabalho e aos retornos excedentes da poupança. Fala-se em modulação da tributação do capital, ou seja, equalizar a oneração do capital tributado na pessoa jurídica e física às outras fontes de renda. Em outras palavras, não tornar a tributação conjunta - nas pessoas jurídica e física - incidente sobre o capital superior a incidente sobre outras fontes de renda. É isso o que realizam aqueles países que tributam o lucro/renda da pessoa jurídica a uma alíquota linear e em sua distribuição para as pessoas físicas oneram esses rendimentos com base em uma tabela mais branda nas alíquotas e na progressividade.

No caso brasileiro, se a tributação sobre a pessoa física apresenta baixa incidência e progressividade, a incidente sobre a pessoa jurídica conta com alíquotas estatutárias bastante elevadas - $34 \%$ - ante a experiência internacional, o que, contudo, não se reflete nas alíquotas efetivas que, em razão do variado espectro de regimes e benefícios, encontram-se, em grande parte dos casos, em patamares inferiores. Soma-se a isso o fato de que existem diferentes tratamentos aos rendimentos do capital com viés favorável aos ativos financeiros perante os ativos produtivos ${ }^{\mathbf{1 6}}$.

Com base nesse cenário, sustenta-se que se deve buscar, como já apontado, a redução da tributação incidente sobre a pessoa jurídica, a eliminação dos tratamentos diferenciados aos rendimentos do capital e a melhor calibragem dos sistemas tributários simplificados, que, associados à tributação sobre lucros e dividendos e à redução dos benefícios decorrentes das deduções com os gastos em saúde e educação e das isenções aos rendimentos oriundos de aposentadorias e pensões, tornaria a tributação direta mais progressiva, reduziria as possibilidades de transfiguração da pessoa física em jurídica, concederia tratamento diferenciado para os investimentos e aprimoraria a focalização dos benefícios dos regimes simplificados nas micro e pequenas empresas.

Com essas alterações, a criação de novas alíquotas marginais superiores aos atuais 27,5\% implicaria maior arrecadação e progressividade do IRPF. Propõe-se a criação de três novas alíquotas: de 32,5\% para rendimentos mensais superiores à R $\$ 8$ mil, de $37,5 \%$ para rendimentos acima de R\$20 mil e, por último, de $40 \%$ para os rendimentos que superem à $\mathrm{R} \$ 40$ mil. Somente a tributação progressiva sobre os lucros e dividendos do IRPF implicaria um crescimento da arrecadação da ordem de $25 \%$ e uma redução do Índice de Gini da renda das pessoas adultas de cerca de $3 \%{ }^{17}$.

Com relação aos impostos patrimoniais, a reduzida importância desses na carga tributária nacional decorre da defasagem dos valores dos imóveis nos registros administrativos das 
prefeituras, da fragilidade das administrações fiscais da maior parte dos municípios, dos obstáculos legais à progressividade e ao nível das alíquotas, entre outros. A defasagem das plantas de valores dos imóveis é presente na maioria dos munícipios, mesmo naquelas com administrações tributárias mais capacitadas, e pode ser, em grande medida, creditada aos empecilhos políticos e jurídicos para a sua atualização. A experiência demonstra que todos os prefeitos que buscaram incrementar a tributação do IPTU tiveram dificuldades em aprovar as medidas nas casas legislativas, com casos de votos contrários das bancadas de esquerda na oposição. Isso quando não sofreram ações judiciais que impediram a concretização das mudanças.

No caso do imposto sobre heranças e doações - o ITCMD -, conta-se hoje com a limitação legal - constitucional - da alíquota máxima de $8 \%$, quando na maioria dos países as alíquotas superiores chegam a atingir $40 \% / 50 \%$. Ademais, até recentemente o judiciário não autorizava a aplicação de alíquotas progressivas tanto no IPTU como no ITCMD, o que implica a quase neutralidade do IPTU, segundo os dados da Pesquisa de Orçamentos Familiares de 2008/0916. Há, portanto, que se alterar a legislação com a elevação da alíquota máxima do ITCMD para um patamar da ordem de $30 \%$, bem como a aplicação de alíquotas progressivas segundo o valor do espólio ou doação.

No que concerne aos impostos recorrentes sobre o patrimônio imobiliário - IPTU e ITR, propõe-se aplicar as normas constitucionais quanto ao cumprimento da função social da propriedade, seja urbana, seja rural, com a aplicação de sanções - maiores alíquotas - aos imóveis que não atendem a esse princípio. Concretamente, imóveis urbanos desocupados, terrenos sem utilização e estabelecimentos agropecuários com baixa utilização das terras, uso de mão de obra em condições similares à escravidão e em descumprimento das normas ambientais devem ser objeto de alíquotas majoradas e progressivas. Em outras palavras, deve-se empregar a tributação sobre tais imóveis como um mecanismo que dificulte seu uso de modo especulativo e antissocial.

\section{Considerações finais}

Para discutir os caminhos que podem ser acessados para melhoria da política fiscal no Brasil, este trabalho buscou apontar as incongruências do sistema tributário e os elementos que afastam o País das boas práticas internacionais, tanto em termos de eficiência quanto em equidade, bem como realçar algumas medidas que têm potencial de contribuir para sua melhoria em ambas as direções.

Como visto, a ineficiência do sistema tributário brasileiro se apresenta em diversos aspectos que vão desde a complexidade dos tributos até especificações mal calibradas e peso desproporcional sobre a pessoa jurídica. Além disso, a confusão de tributos e legislação complexa torna o sistema tributário brasileiro custoso, pouco eficiente e de difícil compreensão. Outro fator é a ênfase tributária brasileira sobre os bens e serviços que são, via de regra, mais sensíveis aos ciclos econômicos e, por isso, contribuem para um caráter pró-cíclico da arrecadação fiscal. A delegação da tributação de bases móveis às instâncias regionais também tem originado conflitos federativos ao possibilitar guerra fiscal. Ademais, as empresas brasileiras são em excesso oneradas na tributação, com incidência sobre a folha de pagamentos estando acima de $40 \%$ ao se considerar as contribuições previdenciárias do empregado e do empregador, o seguro acidente, o Fundo de Garantia do Tempo de Serviço (FGTS), o salário educação e as contribuições do Sistema S. Esse leque de tributos tem efeitos distorcivos para o crescimento econômico ao fragilizar a competitividade das empresas, incentivar a informalidade e a elisão fiscal.

A solução para equacionar esses problemas destacou, portanto, a necessidade de 
uma reforma tributária simplificadora, por meio da fusão (ou substituição) de vários tributos por um IVA e por uma reforma pari passu na tributação direta (renda e riqueza). Tendo em vista que a essência do IVA é a neutralidade, entende-se que o arranjo de medidas propostas tem franco potencial de favorecer o crescimento econômico, uma vez que soluciona o problema da cumulatividade, simplifica o sistema tributário e suaviza a guerra fiscal. Por outro lado, dado que a mudança no IVA sozinha não implica a melhora distributiva do sistema, destacou-se aqui medidas que contribuem para essa direção por reformar o IRPF e os demais impostos que incidem sobre a riqueza acumulada dos indivíduos.

Por fim, vale sublinhar que o mundo aparenta estar adentrando em um novo paradigma da tributação, no qual eficiência e equidade não são mais vistos como um trade off, mas um objetivo que pode ser alçado simultaneamente em prol de sociedades mais justas e solidárias. As propostas, portanto, vão na direção de aprimorar o sistema tributário brasileiro promovendo, concomitantemente, eficiência e equidade. Entende-se, contudo, que ainda falta disposição política e mobilização social para essa batalha.

\section{Colaboradores}

Silveira FG, Passos L e Guedes DR contribuíram para a concepção e planejamento, para elaboração do rascunho, revisão crítica e aprovação final do manuscrito.

\section{Agradecimentos}

Os autores agradecem a Pedro Henrique Oliveira de Souza pelo auxílio na formatação inicial do texto. 


\section{Referências}

1. Gobetti SW, Orair RO. Progressividade tributária: A agenda negligenciada. Texto para Discussão, Instituto de Pesquisa Econômica Aplicada (IPEA), $n^{0}$ 2190, 2016.

2. Mirrlees JA. An exploration in the theory of optimal income taxation. Rev Econ Studies. 1971; 38(2):175208.

3. Atkinson A, Stiglitz JE. The design of tax structure: direct versus indirect taxation. J Public Econ. 1976; 6(1-2):55-75.

4. Barbosa ALN, Siqueira RB. Imposto ótimo sobre o consumo: resenha da teoria e uma aplicação ao caso brasileiro. Rio de Janeiro: Ipea, 2001. (Texto para discussão $\left.n^{\circ} 811\right)$.

5. Lagemann E. Tributação Ótima. Ensaios FEE. 2004; 25(2):403-426.

6. Gobetti S. Tributação da renda do capital e progressividade: o que fazer? In: Afonso JR, Lukic MR, Orari RO, Silveira FG, organizadores. Tributação e desigualdade. Belo Horizonte: Letramento; 2017. p. 159-192.

7. Ramsey F. A contribution to the theory of taxation. Economic Journal. 1927; 37(145):47-61.

8. Diamond PA, Mirrlees, JA. Optimal taxation and public production: I / II. Am Econ Rev. 1971; 61:261278.

9. Piketty T. O Capital no Século XXI. Rio de Janeiro: Intrínseca; 2014.

10. Fundo Monetário Internacional. Fiscal monitor. Fiscal Monitor: Tackling Inequality. Washington, October 2017.

11. Diamond P, Saez E. The case for a progressive tax: from basic research to policy recommendations. $J$ Econ Persp. 2011; 25(4):165-190.
12. Appy B, Messias L. O elevado grau de litigiosidade tributária no Brasil: diagnóstico e medidas de encaminhamento. O Estado de São Paulo. 24 de março, 2014. [acesso 2018 set 18]. Disponível em: http://economia.estadao.com.br/ noticias/geral,litigiosidadetributaria-no-brasil-imp-,1141652.

13. Appy B. Por que o sistema tributário brasileiro precisa ser reformado. Revista Interesse Nacional. [acesso em 2018 set 18] 2015; 8(31). Disponível em: https://edisciplinas.usp.br/pluginfile.php/4105024/mod_resource/content/0/Appy_ Tributa\%C3\%A7\%C3\%A3o_Revisado.pdf.

14. Souza JM. Tributos sobre consumo: novo modelo para um Brasil mais justo. In: Fagnani E, organizadores. A Reforma Tributária Necessária: diagnóstico e premissas. Brasília, DF: ANFIP: FENAFISCO; São Paulo: Plataforma Política Social; 2018. p. 501516.

15. Fernandes RC, Campolina B, Silveira FG. Impacto distributivo do imposto de renda. In: Afonso JR, Lukic MR, Orari RO, et al, organizadores. Tributação e desigualdade. Belo Horizonte: Letramento; 2017.

16. Orair R, Gobetti S. Reforma tributária: princípios norteadores e propostas para o debate. In: Negri JÁ, Araújo BC, Bacelette R. Desafios da nação: artigos de apoio. Brasília, DF: Ipea; 2018. 2. v.

17. Silveira FG. Equidade fiscal: impactos distributivos da tributação e do gasto social. Brasília, DF: Brasil: ESAF-Tesouro Nacional; 2012.

Recebido em 16/08/2018

Aprovado em 17/09/2018

Conflito de interesses: inexistente

Suporte financeiro: não houve 